REGINE PRANGE

\title{
Grenzen des Verstandes Paul Klee, Leonardo da Vinci und die Ratio des ästhetischen Bildraums ${ }^{1}$
}

\section{Einleitung}

Die Frage danach, ob und inwiefern Bilder Medien der Erkenntnis sind, wird aktuell breit diskutiert im Rahmen des von zahlreichen Disziplinen getragenen Projekts einer universalen Bildwissenschaft. Deren Ziel ist es, sämtliche Bildgattungen, Gebrauchsbilder ebenso wie Kunstbilder, in ihren Gesetzlichkeiten zu erfassen. ${ }^{2}$ Vor dem Hintergrund dieses Forschungsspektrums und einigen seiner dominanten Tendenzen widersprechend möchte ich meine Position und Fragerichtung zunächst präzisieren. Drei Thesen seien an den Anfang gestellt.

1. Bildliche Strukturen, in denen sich Erkenntnis vermittelt, sind wie alle anderen kulturellen Formen historisch-gesellschaftlichen Umwälzungsprozessen unterworfen, die den Inhalt ebenso wie die Wege der Erkenntnis qualitativ verändern. Besonderes Interesse muss daher den Transformationen und Zäsuren in der Geschichte der Bildproduktion gelten und nicht ihren mutmaßlichen Konstanten. In diesem Zusammenhang ist an einer Unterscheidung festzuhalten, die Walter Benjamin eingeführt hat und die noch Hans Beltings Buch Bild und Kult (1993) zu Grunde liegt: die Differenz zwischen einer kultisch-religiösen Bildproduktion und einer ästhetischen. ${ }^{3}$

2. Innerhalb der neuzeitlichen Geschichte des Kunstbildes ist eine weitere Bruchstelle erkennbar, die mit dem Ende der akademischen Normen und der For-

1 Anregungen der Diskussionsteilnehmer in Greifswald sowie in Offenbach und in Frankfurt am Main, wo überarbeitete Versionen des Vortrags präsentiert worden sind, wurden eingearbeitet. Namentlich Hans Zitko und Christian Janecke verdanke ich wichtige weiterführende Hinweise.

2 Eine semiotische Konzeption zu einer interdisziplinären Bildwissenschaft legte Klaus Sachs-Hombach 2005 vor. Im Rahmen der Disziplin Kunstgeschichte hat insbesondere Horst Bredekamp einen universalen Bedeutungsanspruch von Bildern vor aller verbal-begrifflichen Äußerungsform auch in praktisch-politischen und wissenschaftlichen Bereichen geltend gemacht. Siehe die gemeinsam mit Gabriele Werner herausgegebene Zeitschrift Bildwelten des Wissens.

3 Benjamin prägte für diese historische Differenz die Begriffe »Kultwert« und »Ausstellungswert«. Siehe insbesondere Walter Benjamin, Gesammelte Scbriften, hrsg. von Rolf Tiedemann und Hermann Schweppenhäuser, Bd. 1/2, Das Kunstwerk im Zeitalter seiner technischen Reproduzierbarkeit [Erste Fassung], Frankfurt am Main 1991, S. 445. Zu Beltings Anlehnung an diese Antithese s. Regine Prange, Das ikonoklastische Bild. Piet Mondrian und die Selbstkritik der Kunst, München 2006, S. 335, Anm. 16. 
mierung der künstlerischen Avantgardebewegungen im 19. und 20. Jahrhundert assoziiert ist. Die besondere intellektuelle Kapazität avantgardistischer Kunst am Beispiel Klees wird im Zentrum meines Vortrags stehen. Ihre Bedeutung ist jedoch nur zu ermessen, wenn

3. die Bildräumlichkeit als entscheidende Instanz für die kognitive Funktion der ästhetischen Bilder verstanden wird. Die magisch-kultische Stufe der Bilderproduktion ist hingegen durch Flächigkeit und eine höchstens partielle Plastizität charakterisiert. Der Bildträger, sei es die Kirchenwand, sei es eine Altartafel, wird in seiner Materialität nicht geleugnet, denn das Mysterium der christlichen Heilsvermittlung war an den als solchen heiligen Ort gebunden, an die liturgischen Zeremonien, an denen die Gemeinde partizipierte und in welchen die Bilder ihre Funktion erhielten. Dass der fiktionale Raum als Bedeutungsträger ins Spiel kam, ist offenbar der Ablösung eines primär religiös definierten Gemeinwesens und seiner Denkhaltung durch eine partiell laizistisch geprägte bürgerliche Gesellschaft geschuldet, welche ihre Vorstellung von Wahrheit und Erkenntnis nicht mehr allein durch Glaubensinhalte und deren visuelle Chiffrierung gesichert sah, sondern zusätzlich einer im Bild hergestellten Wirklichkeitsillusion bedurfte, um sich von der Objektivität und Authentizität der dargestellten Sache zu überzeugen.

Einen in sich geschlossenen, systematisch auf den Fluchtpunkt hin fokussierten Illusionsraum hat erstmals Masaccio in seinem Trinitätsfresko in der Florentiner Kirche Santa Maria Novella um 1420 präsentiert. ${ }^{4}$ Erst in jener Zeit entwickelt eine Künstlerschaft Methoden, die sich der Geometrie und der Optik bedienen, um das Bild von seiner Umgebung abzugrenzen als eine scheinbar autonome andere Welt, es zugleich auch zum Betrachter hin zu öffnen. Durch ihren Blick aus dem Bild und die auf Christus am Kreuz weisende Rechte appelliert Maria als Vermittlerfigur an die Betrachter und macht so den Raum, der durch die Triumphbogen-Architektur und das Kassettengewölbe gebildet wird, imaginär zugänglich. Auf diese Formation einer ästhetischen Grenze möchte ich mein Augenmerk richten. Sie ist auch der berühmten, von Leon Battista Alberti eingeführten Metapher inhärent, die das Bild mit dem Fenster vergleicht und damit aussagt, ${ }^{5}$ dass der Bildrahmen nicht nur als Grenze wahrgenommen wird, sondern auch als Schwelle zu einem potentiell unendlichen Raum, der sich jenseits des Rahmens fortzusetzen scheint. Die höchste Idee - in Masaccios Fresko die Idee der göttlichen Trinität - ist bezogen auf ein einzelnes Betrachtersubjekt, während das Göttliche im früheren Mittelalter nicht primär durch subjektive Anschauung, sondern durch die kollektive Kulthandlung

4 S. hierzu den zentralen Aufsatz von Wolfgang Kemp, „Masaccios 'Trinitäts im Kontext«, in: Marburger Jabrbuch für Kunstwissenschaft 21, 1986, S. 45-72.

5 Leon Battista Alberti, Della Pittura [1435/36]. Über die Malkunst, hrsg. von Oskar Bätschmann und Sandra Gianfreda, Darmstadt 2002, S. 93. „Als Erstes zeichne ich auf der zu bemalenden Fläche ein rechtwinkliges Viereck von beliebiger Größe; von diesem nehme ich an, es sei ein offenstehendes Fenster, durch das ich betrachte, was hier gemalt werden soll [...].« 
Abb. 1: Leonardo da Vinci, Johannes der Täufer, ca. 1508-10, Paris, Louvre (vgl. Farbtafel 39)

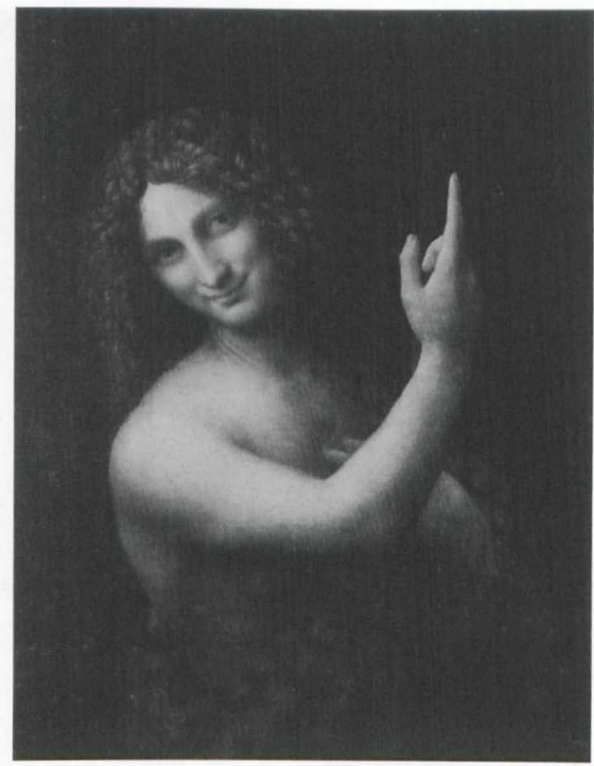

an einem geheiligten Ort repräsentiert wurde. Ein sehr bekanntes, übrigens auch von Paul Klee kommentiertes Beispiel für einen solchen kultischen Bildgebrauch ist die 1290-1295 entstandene Petrusstatue des Arnolfo di Cambio in St. Peter in Rom, deren »abgeküsste Zehen $\aleph^{6}$ von den rituellen Berührungen der Gläubigen zeugen. Das entwickelte Kunstbild stellt gegenüber einer solchen taktilen Begegnung mit der heiligen Person, deren Stellvertreter das Kultbild ist, eine einerseits, in der Beschränkung auf die optische Qualität, distanziertere, andererseits, durch die Adressierung des Betrachters, individualisierte Form der sinnlichen Partizipation am Heilsversprechen dar. Es ist als Versuch zu verstehen, die ältere magische Dimension für eine modernisierte Gesellschaft zu reformulieren, die ihren eigenen Augen, ihrer eigenen Erfahrung trauen will. Die metaphysische Vorstellung eines unendlichen Raums wird gewissermaßen durch die Perspektivkonstruktion rationalistisch begründet und so einer empirisch ausgerichteten Haltung angepasst, die am Bild nicht bloß die schon fixierten Wahrheiten innerlich memorieren, sondern sie erleben, intensiv erfahren will.

Die gesellschaftliche Voraussetzung für diese mythische Einheit des Bildes, in der Gott und Mensch gleichsam in einer Sphäre zusammentreten, schwindet mit der historischen Zersetzung der Feudalgesellschaften, in deren Folge die Identität

6 Paul Klee, Tagebücher 1898-1918. Textkritische Newedition, hrsg. von der Paul-Klee-Stiftung Kunstmuseum Bern, bearb. von Wolfgang Kersten, Stuttgart 1988, S. 83, Nr. 285 (31.10.1901). Zur Kommentierung der Begegnung Klees mit der Kultstatue s. Charles W. Haxthausen, "Zwischen Darstellung und Parodie: Klees rauratische Bilder«, in: Oskar Bätschmann und Josef Helfenstein (Hrsg.), Paul Klee. Kunst und Karriere. Beiträge des Internationalen Symposiums in Bern, Bern 2000, S. 9-26. 


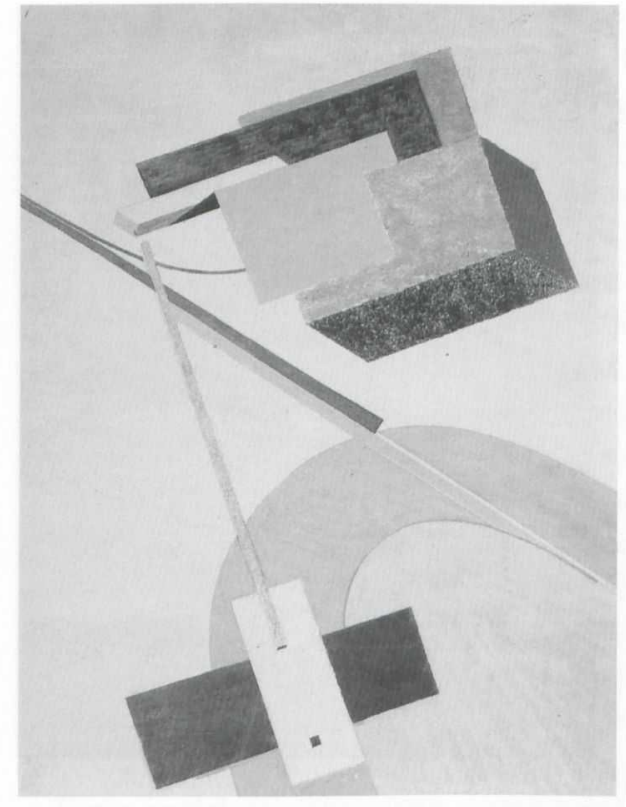

Abb. 2: El Lissitzky, Proun 23N (B111), Ludwigshafen, Wilhelm-Hack-Museum, $1920 / 21$

von göttlicher Wahrheit und weltlicher Herrschaft ihre Verbindlichkeit verlor, auch wenn bis heute dieses vormoderne Denkmodell keineswegs ausgedient hat, auch in der Kunsttheorie nicht, wie wir noch sehen werden. Die avancierte Malerei der Moderne löst spätestens mit Paul Cézannes `Fleckenmalerei das imaginäre Raumkontinuum auf und mit ihm die Anschaulichkeit einer höchsten Idee. Im Zentrum der Moderne-Debatte steht daher die Sinnfrage. Können Bilder, die keine würdigen Gegenstände mehr präsentieren, die der Schönheit des menschlichen Körpers entsagen, noch den Anspruch erheben, Ausdruck höchster Ideen zu sein?

Paul Klees Aquarellzeichnung Grenzen des Verstandes (Farbtafel 44), die im Mittelpunkt der nun folgenden Betrachtungen steht, stellt diese Sinnfrage, indem sie die metaphysischen Optionen des Bildraums mit den Mitteln von Farbe und Linie kritisch reflektiert. Es folgen nun zwei Abschnitte. Zunächst wird Klees Bild im Kontext der Kunstmoderne erörtert; dann wird auf der Grundlage eines kurzen Exkurses zur reflexiven Qualität des Bildraums eine vergleichende Betrachtung bildräumlicher Strukturen bei Klee und Leonardo angeschlossen. Dessen Johannes der Täufer (Abb. 1) steht hier als Exempel für die entfaltete Bildräumlichkeit des sklassischen` Tafelbildes.

\section{Grenzen des Verstandes}

Klees Werk Grenzen des Verstandes (1927) bezieht auf subtil-ironische Weise Stellung gegen den utopischen Rationalismus des Bauhauses, der Institution, welcher Klee seit 1921 als Lehrer wie als Künstler angehörte, mit wachsender Skepsis, die 
Abb. 3: El Lissitzky, Selbstporträt (Konstrukteur), 1924

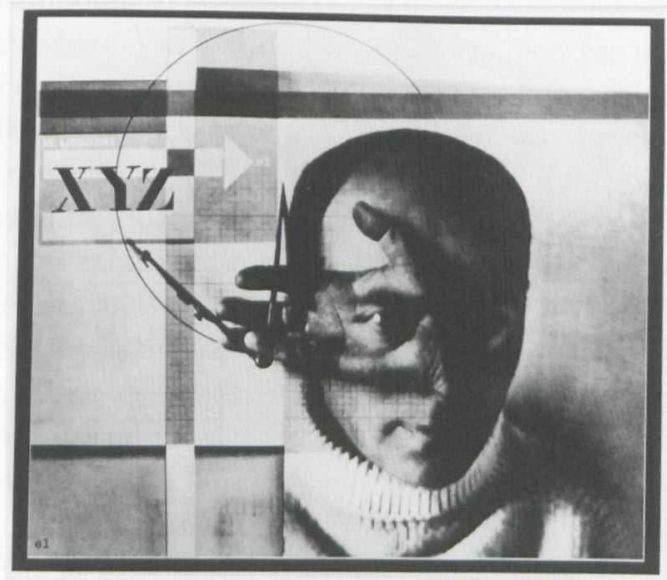

zunehmend technologische Tendenz betreffend. ${ }^{7}$ Der kreidig weiße Bildgrund und die Exaktheit der geometrischen Formationen verweisen auf konstruktivistische Vorbilder - etwa El Lissitzkys Proun-Darstellungen der frühen 1920er Jahre (Abb. 2) - und damit auf ein bildnerisches Vokabular, das der abstrakten geometrischen Form vertraut, aus ihr eine durchaus ideale Ordnung ableitet, die der unvollkommenen Wirklichkeit aufgetragen werden und damit einer neuen Gesellschaft zugleich Form und Geist mitteilen sollte. ${ }^{8}$ Bekanntlich hat sich die russische Avantgarde nach der Oktoberrevolution als entscheidende Institution für die proletarisch-egalitäre Umgestaltung des gesellschaftlichen Lebens gesehen, bevor die Doktrin des Sozialistischen Realismus wieder die Formeln der klassizistischen bürgerlichen Tradition einsetzte. Aus El Lissitzkys Fotografie Konstrukteur (Abb. 3), einem Selbstporträt von 1924, spricht immer noch das Vertrauen, mit dem Zirkel in der Hand, der sich hier mit dem Auge des Künstlers durchdringt, eine neue Welt

7 Nähe und Distanz von Klees Werk zum Konstruktivismus erörtert in der bislang einzigen ausführlichen Bildanalyse Cathrin Klingsöhr-Leroy, Paul Klee in der Pinakothek der Moderne. Bestandskataloge zur Kunst des 20. Jabrbunderts, hrsg. von der Pinakothek der Moderne und den Bayerischen Staatsgemäldesammlungen, Bd. 2, München 1999, S. 150f. Zu diesem Aspekt auch Ralph Melcher, »Die Konstruktion des Geheimnisses«, in: Ausst. Kat. Paul Klee. Tempel - Städte - Paläste, Saarbrücken 2006, S. 156-165, der das Bild als Auftakt zur abstrakten Werkgruppe der »verspannten Flächen« versteht, die Klee 1930, etwa mit Schwebendes (1930. 220), entwickelt hat. Thr Kennzeichen ist die simultane Darstellung rational-perspektivischer und irrationaler Raumverbindungen. Durch die »Konstruktion des Geheimnisses« beziehe Klee kritisch Stellung gegen die von Moholy-Nagy initiierte funktionalistische Tendenz des späten Bauhauses.

8 Auf der Ersten Russischen Kunstausstellung in Berlin wurden drei Proun-Gemälde gezeigt. Ausst. Kat. Stationen der Moderne. Die bedentendsten Kunstausstellungen des 20. Jahrbunderts in Deutscbland, hrsg. von der Berlinischen Galerie und dem Museum für moderne Kunst, Photographie und Architektur im Martin-Gropius-Bau Berlin, Berlin 1988, S. 191. 


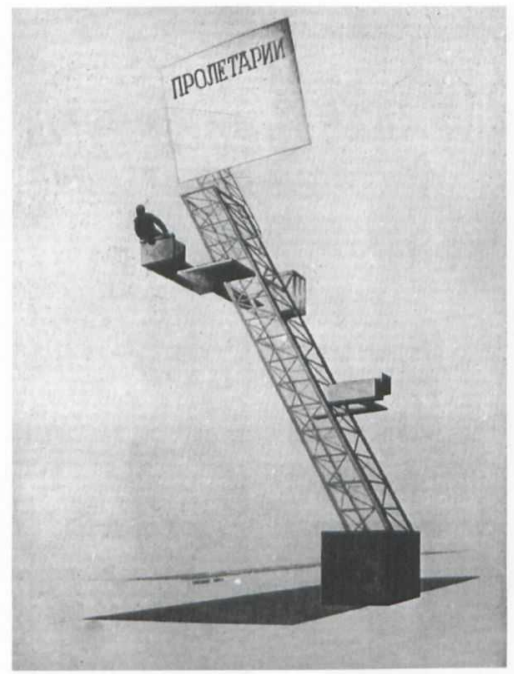

Abb. 4: El Lissitzky, Lenintribüne (in Zusammenarbeit mit Ilja Tschaschnik), 1920-1924

erschaffen zu können. Das wahre Sehen, so die Botschaft dieser Doppelbelichtung, bedient sich mathematischer, wissenschaftlicher Verfahren.

Klees Werk erscheint wie eine Parodie auf dieses stolze Selbstbildnis, das die künstlerische Kontrolle über die Ordnung des Weltalls verheißt. ${ }^{9}$ Denn Klee zeigt eine ganz andere, grotesk deformierte Durchdringung von menschlichem Gesicht und geometrischer Konstruktion, weit abgerückt von der idealen Kreisform im oberen Bildbereich.

Auch das Leitermotiv bringt ein Modell El Lissitzkys in Erinnerung - die Lenintribüne (Abb. 4), fertig gestellt zu Beginn der 20er Jahre während eines Kuraufenthaltes in der Schweiz. Und auch in diesem Vergleich ist auffällig, dass El Lissitzky die Diagonale funktional und zugleich als ein Triumphzeichen einsetzt, das von der dynamischen Progression der Weltgeschichte kündet, während Klee der Diagonalen eine fragile, uneindeutige Gestalt gibt. Nicht der kontrollierende, raumgreifende Triumph rationalen Denkens, sondern, wie der Titel ausdrücklich bekundet, seine Behinderung und Begrenzung, ja sogar seine Lächerlichkeit, sind Klees Themen.

9 El Lissitzkys Selbstporträt erschien erst 1928 im Dezemberheft der Zeitschrift Gebrauchsgraphik. Siehe Margareta Tupitsyn, „Zurück nach Moskau«, in: dies. (Hrsg.), Ausst. Kat. El Lissitzkey. Jenseits der Abstraktion. Fotografie, Design, Kooperation. Sprengel Museum Hannover, 17. Januar - 5. April 1999, München u.a. 1999, S. 25-51, hier S. 30 Abb. 7. Dass Klee es zuvor schon kennengelernt hat, ist möglich, aber bisher nicht belegt. Seine satirische Haltung gegenüber der konstruktivistischen Ästhetik setzt jedoch nicht unbedingt seine Kenntnis bestimmter Werke voraus. Möglich ist auch ein anderes Vorbild. Eine vergleichbare Montage von Künstlerauge und Zirkel, die das Sehen mit der Konstruktion symbolisch identifiziert, findet sich z.B. in El Lissitzkys Collage Tatlin bei der Arbeit am Monument der Dritten Internationale, einer Illustration zu Ilja Ehrenburgs 6 Erzäblungen mit leichtem Schluß, die 1922 publiziert wurden. Ebd., S. 69, Tafel 3. 
Mit diesen Verweisen ist die Bildfindung noch keineswegs erschöpft. Vielmehr ist es die zunächst kaum durchschaubare Vielzahl und Verdichtung von eigenen und fremden, überlieferten und modernen künstlerischen Motiven und Formen, die Grenzen des Verstandes zu einem bildkritischen Schlüsselwerk der klassischen Moderne macht. Klee bricht auf ganz andere Weise als El Lissitzkys Fotocollagen mit dem geometrischen Purismus der Abstraktion, indem er ihn mit zwei weiteren historisch früheren Bildformeln amalgamiert: der kubistischen Fragmentierung des Bildraums und der sie vorbereitenden Stufe des romantischen Sehnsuchtsbildes, das den Raum in eine diesseitige und eine ideale Sphäre spaltet. Die rote, kreisförmige Scheibe im oberen Bildbereich bezeichnet im Sinne dieser letzteren Bildformel ein Gestirn, womit dieses ,Oben den Bereich des Kosmischen und zugleich Idealen signifiziert. Fragile Leitern aus der unteren irdischen Sphäre winden sich herauf, ausgehend von dem verschachtelten Linienkonglomerat, das einen frontal gesehenen menschlichen Kopf evoziert. Vor allem zwei einander gegenüberliegende Kegelgebilde scheinen dem Linienkomplex Augen zu verleihen und motivieren so eine physiognomische Lesweise. ${ }^{10}$ Sie wirken zudem wie gebündelte Strahlen, als vitale, gleichsam aktive Quellen der Linienkonstruktion; durchaus entsprechend der Aussage von El Lissitzkys Selbstporträt, doch im Gegensatz zu jener zerstörerisch auf die menschliche Gestalt übergreifend. Damit rückt die Zitierung kubistischer Verfahren in den Vordergrund. Die gezackte Außenkontur des Gesichts desavouiert jede organische Geschlossenheit und rekapituliert auf diese Weise die Methode Picassos und Braques. Auch diese ironisiert Klee, denn er untergräbt den analytischen Ernst und den Willen zur formalen Einheit, mit dem etwa Picasso 1909 die Frau mit den Pfirsichen (Abb. 5) zergliedert und mit ihrer Umgebung zu einem flachen, facettierten Raum verschränkt hat. Klee inszeniert die Aufhebung der Körpergrenzen, das entscheidende kubistische Bildmittel, nicht als virtuose Konstruktion, sondern als ein groteskes mechanisches Spiel. Entgrenzung ereignet sich wie von selbst; die vielfach verschachtelten und verdoppelten transparenten sAuswüchse folgen keiner konstruktiven Logik und Einheit, sondern scheinen sich wie in einem Kristallisationsprozess selbst hervorzubringen. ${ }^{11}$ Die Linie vollzieht permanent einen Identitätswechsel durch, vom flächigen Netz zur perspektivischen Kontur, von abstrakter zu zeichenhafter

10 Eine ähnlich ambivalente Wirkung schuf Klee, wenn auch formal auf anderen Prinzipien beruhend, in Physiognomische Kristallisation (Paul Klee, „Über die moderne Kunst«, Vortrag aus Anlass einer Ausstellung seiner Werke im Jenaer Kunstverein am 26. 1. 1924, in: Günter Regel [Hrsg], Paul Klee. Kunst-Lehre. Aufsätze, Vorträge, Rez̧ensionen und Beiträge zur bildnerischen Formlebre, Leipzig 1995, S. $70-85$, hier S. 15.)

11 Hiermit ist Klees Nähe zur »Écriture automatique« des Surrealismus berührt, die Kunst als Medium der Erkenntnis neu zu begründen versuchte, indem sie unbewussten, nicht durch Konvention festgelegten Energien und Ideen Ausdruck verschaffen wollte. In den frühen Veröffentlichungen wird Klee v.a. in dieser Hinsicht gewürdigt. Grenzen des Verstandes war z.B. 1931 in der Ausstellung German Painting and Sculpture im Museum of Modern Art in New York ausgestellt. Im Begleittext heißt es: »Like them [die Pariser Surrealisten] he [Klee] is concerned primarily with an invented world of incredible paradox or of spontaneous fantasy.« Zu Klees künstlerischem und konzeptu- 


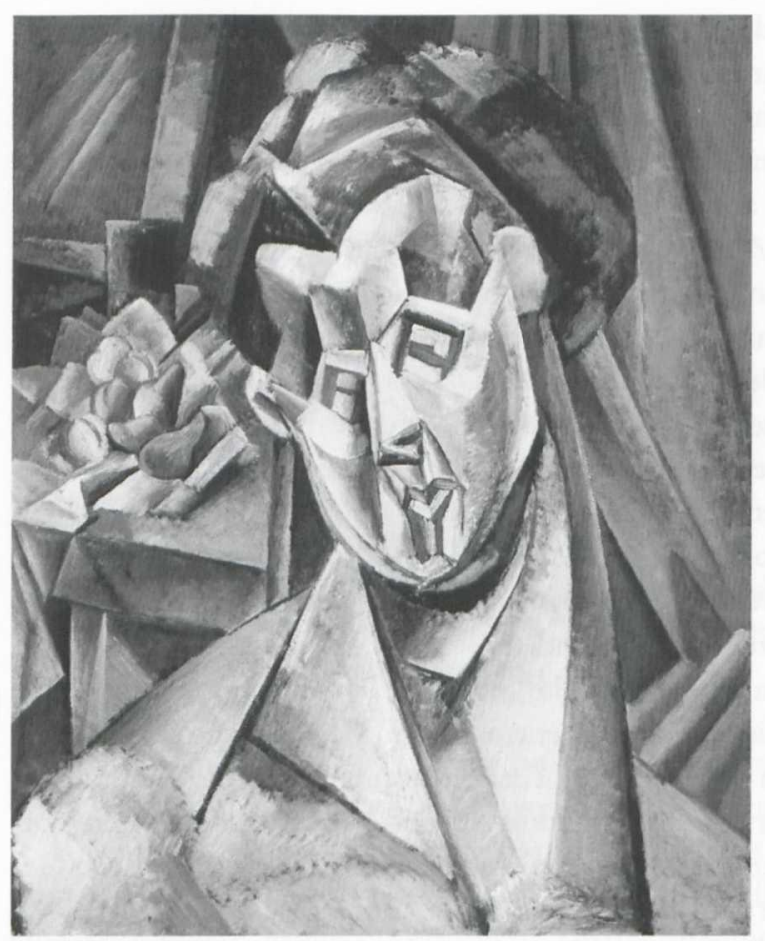

Abb. 5: Pablo Picasso, Fran mit Pfirsichen

(Fernande), 1909 (vgl. Farbtafel 40)

Gestalt. Auch das Verhältnis zur Grundfläche ist weit komplizierter, als es zunächst den Anschein hat. Die Zeichnung steht nicht als erhabenes Konstrukt über dem Bildträger. Sie reflektiert in ihrer Vielfarbigkeit die Ocker-, Rot- und Gelbtöne des weißlichen Bildgrunds, die sich wie eine Aureole um den lilafarbenen sSchatten der Gestirnscheibe ausbreiten - Zitierung eines Weltengrundes, aus dem der Künstler als Erfinder - auch Klees Signatur ist violett - seine Herkunft zu bestimmen scheint. ${ }^{12}$

Dieser Rekurs auf eine naturanaloge Entstehung von Kunst ist bereits Teil der schon angeführten romantischen Ikonographie, die Klee mit seiner zeichnerischen und malerischen Erforschung des Bildraums ins Verhältnis setzt. Kristalliner Kopf und flächiges Gestirn sind in eine Relation zueinander gebracht, die das romantische Sehnsuchtsbild aufruft - die moderne Allegorie des Menschen in seinem unerfüllbaren Streben nach dem transzendenten Sinn seiner Existenz. Diese Bildformel, deren exemplarische Prägung man sich anhand von Caspar David Fried-

ellem Verhältnis zum Surrealismus ausführlich Regine Prange, „Das utopische Kalligramm. Klees

Zeichen und der Surrealismus«, in: Bätschmann und Helfenstein 2000 (s. Anm. 6), S. 204-225.

12 Diese Beobachtung verdanke ich Christian Janecke. 


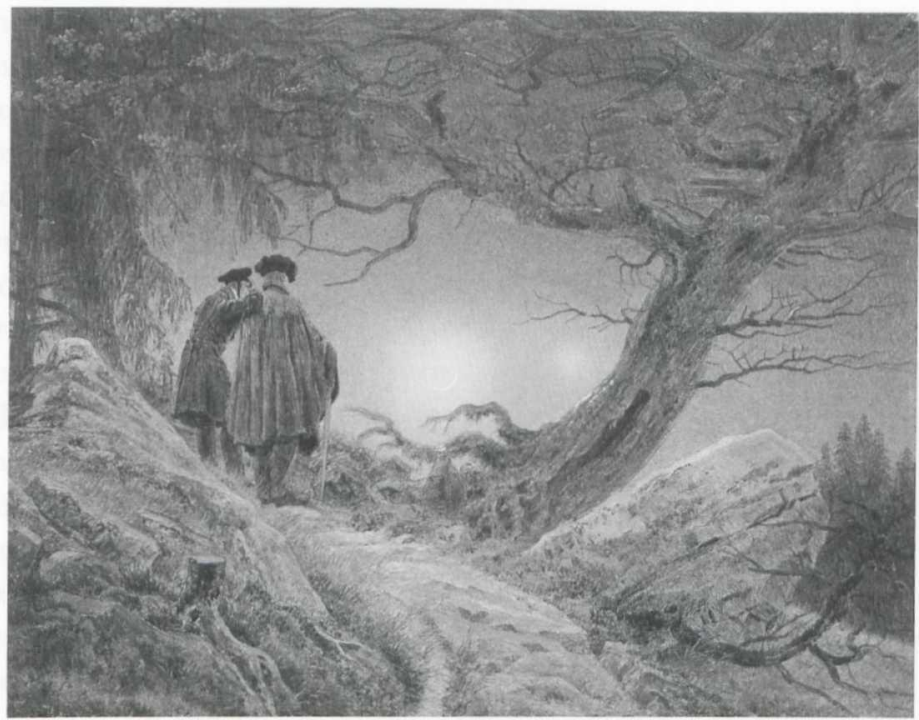

Abb. 6: Caspar David Friedrich, Zwei Männer in Betracbtung des Mondes, 1819 (vgl. Farbtafel 3)

richs Zwei Männer in Betracbtung des Mondes (Abb. 6) verdeutlichen mag, ist bereits ein Kunstsymbol, eine negative Darstellung der Unendlichkeit, die im zentralperspektivisch konstruierten Bild noch fassbar schien. ${ }^{13}$ Hier wie dort ist der utopische Zielort als solcher unbestimmt. Entgegen der Sicherheit, die der Bildttitel vermittelt, ist das Blickziel der Männer in Friedrichs Bild nicht klar. Bei Klee ist es ähnlich. Die Leiter erreicht das Gestirn nicht. Zugleich wird dessen Bestimmung als transzendentes Ziel ${ }^{14}$ durch andere Mittel in Frage gestellt, auf die nun einzugehen sein wird.

13 Die Beziehung zwischen dem Subjekt und dem unendlichen Raum hat Oswald Spengler, Der Untergang des Abendlandes, München 1993 (zuerst 1918-1922), S. 227, als Urform der abendländischen Seele gedeutet. Panofsky interpretierte 1924/1925 (s. Anm. 17), offenbar in Anlehnung an diesen Text, die Perspektive als symbolische Form des Unendlichen.

14 In einer Tagebucheintragung zum Ostersonntag 1914 während des Aufenthalts in St. Germain bei Tunis bestimmt Klee den Vollmond zum Symbol eines manderen«, durch die Kunst vollendeten Ichs: »Er [der Mond] wird meine Braut sein, mein anderes Ich. Mich zu finden ein Anreiz.« Zur kunstsymbolischen Metaphorik dieses Motivs s. Christine Hopfengart, »Alpengipfel, Pyramide und Musensitz. Ad Parnassum als metaphorische Landschaft«, in: dies. (Hrsg.), Ad Parnassum - auf dem Prïfstand. Kunsthistorische und konservatorische Fragen rund um ein berïbmtes Bild. Beiträge des Kolloquiums im Kunstmuseum Bern vom 22. Oktober 2006, S. 25-36, hier S. 30f. Seit 1915 ergänzte Klee seine kubistischen Kompositionen durch das pseudokindliche Zeichenvokabular sonne, Mond und Sterner. Die insbesondere dem Kreismotiv zugewiesene Fähigkeit zur Verdichtung von konstruktiver Abstraktheit und kosmischer Bedeutungsfülle entspricht der metaphorischen Synthese von Kunst und Natur im Kristallmotiv und artikuliert exemplarisch die Absicht, in der Kunst das Gesetz des Lebens selbst zum Ausdruck zu bringen. 


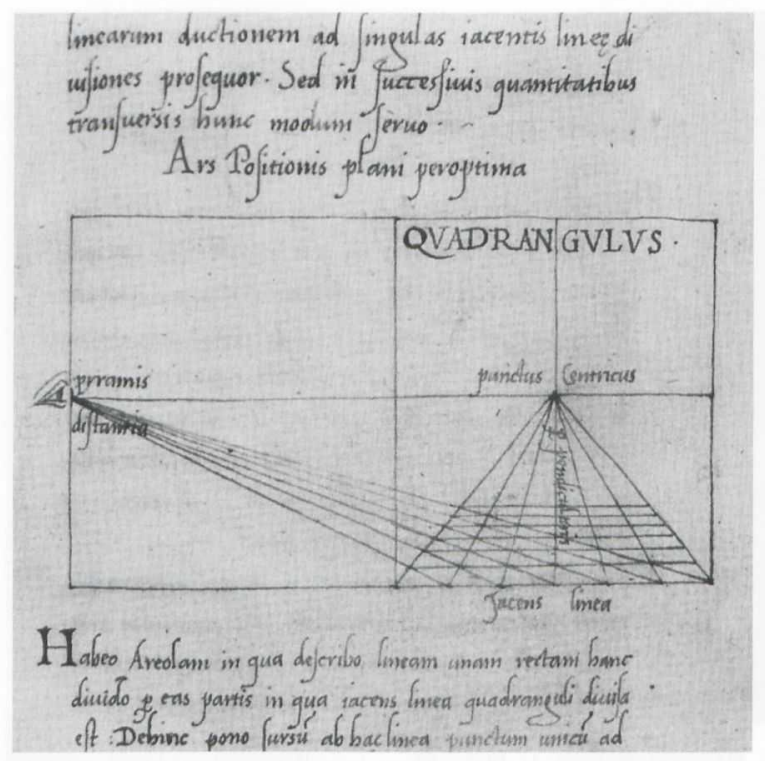

Abb. 7: Leon Battista Alberti, Albertis perspektivische

Konstruktion, Ausschnitt aus einem Manuskript

Klee führt das Thema als solches ad absurdum, indem er all die von ihm selbst zitierten Grenzziehungen - zwischen dem Diesseits und dem Jenseits, dem Körper und dem Raum - durch die formale Gestaltungsweise wiederum negiert. Das Gestirn ist, wie sich bei näherer Betrachtung zeigt, nicht eindeutig das unerreichbar Andere, führt doch eine gerade Linie zur unteren Leiterdiagonalen, die es als Anhängsel, wohl gar als Produkt jener Konstruktion ausweist, die zu seiner Erreichung ersonnen war. Man mag an einen Luftballon denken, aber auch an ein Pendel. Schon diese beiden Assoziationen setzen die natürlichen, durch Mensch und Gestirn aufgerufenen Bedingungen der Schwerkraft und die gewöhnlichen Richtungsverhältnisse außer Kraft.

Gegensatzpaare werden einzig und allein definiert, um als solche in Frage gestellt zu werden. Subjekt und Objekt der Erkenntnis sind dadurch einander angeähnelt, dass das kreisförmige Auge unten die Form des Gestirns oben wiederholt. Das Sehen erweist sich zugleich als passiv und aktiv: Erscheint nämlich der Blick aus der Augenscheibe rechts aufgrund der konzentrisch verdichteten Binnenzeichnung passiv empfangend, wirkt das linke Auge wie ein Fernrohr zur Seite gedreht, als ein kinematographisches Pendant, von dessen aktiver Strahlung unmittelbar die geometrische Formbildung ihren Ausgang nimmt. Man kann diese Gleichung zwischen Wahrnehmung und Gestaltung als ironische Übersetzung von El Lissitzkys Identifizierung von Künstlerauge und zirkelführender Künstlerhand deuten. Der ihr 
inhärente Anspruch auf den Rang eines göttlichen Weltbaumeisters wird gleichsam wörtlich genommen. ${ }^{15}$

Darüber hinaus berührt Klee deutlich das neuzeitliche Fundament dieser mythischen Idee vom schöpferischen Sehen des Künstlers, denn er stellt die oben erwähnte Verbindung zwischen dem Unendlichkeitssymbol des Gestirns und der Perspektivkonstruktion sichtbar her. Das projektorartige Ausstrahlen des linken Auges ruft die von Alberti und seinen Nachfolgern angefertigten zeichnerischen Demonstrationen der Sehstrahlen (Abb. 7) auf, die im Auge zusammenlaufen oder von ihm ausgehen, um die dingliche Welt zu erfassen. Die lineare Strahlung des Augkegels geht direkt in das konstruktive Netz aus dünnen Linien über, das den Kopf, die Leitern, aber auch den Umriss der roten Kreisscheibe bildet. Damit unterläuft Klee nicht nur kategoriale Getrenntheit von konstruktivem Entwurf und Ausführung, sondern mit ihm auch die entscheidende Differenz zwischen Subjekt und Objekt. Was das Sehen als Wahrnehmungsform und Grundlage der Kunst und der Wissenschaft auszeichnet, nämlich die objektivierende Unterscheidung von Ich und Welt, wird durch die metamorphotische Verwandlung der Linien, die einmal das Instrument zur Raumdarstellung und ein andermal diesen Raum selbst vorstellen, verneint. ${ }^{16}$

Spätestens hier sollte deutlich geworden sein, dass Klee in Grenzen des Verstandes auf das Mysterium des künstlerischen Bildes reflektiert, indem er seine Kernbehauptung - die Abgrenzbarkeit von Subjekt und Objekt, Mensch und Raum - auf verschiedenen Ebenen inszeniert und dementiert. Das Thema seines Bildes, an dem auch die modernen Stile bei ihrer Zitierung gemessen werden, ist die mit Hilfe der darstellenden Geometrie hergestellte Evidenz eines quasinatürlichen Wahrnehmungsbildes, das den vermittelten Bedeutungen, welchen auch immer, jeden arbiträren Charakter nahm. Es geht um die Macht der Perspektive, etwas als individuellen, sinnlichen Ausdruck und Eindruck zu präsentieren, was in Wahrheit gesellschaftliches Konstrukt ist. Klee denkt in seiner Kunst über die präsentische Qualität des Kunstbildes nach, die man kurz als Evokation sinnlich-räumlicher Gegenwart ideeller Gegenstände bestimmen kann.

Das der Romantik entlehnte Motiv ıMensch versus Unendlichkeit des Raums leistet dabei als solches schon ein Stück historischer Analysearbeit, denn in ihm sind alle christlich kodierten Bildaufgaben in ihrem grundlegenden Gehalt verdichtet. Die irdische Sphäre als eine Sphäre des Mangels sucht - dies die Grundform des Wissensdranges - nach ihrer Vervollständigung, ihrem Heil. Klees ambivalentes Himmelsgestirn ersetzt gewissermaßen die Versammlung der Heiligen, die einst von den alten Meistern auf Wolken entrückt, aber auch der gefühlten Augenzeugenschaft des

15 Vgl. die Darstellung von Gott als Weltarchitekt mit Zirkel. Bible moralisé, 1230/40, Cod. 1179, fol. 1, Österreichische Nationalbibliothek.

16 Die groteske Interaktion von Figur und perspektivischer Konstruktion findet sich auch in den Ölfarbezeichnungen Perspective-Spuk $(1920,174)$ und Zimmerperspektive mit Einwobnern $(1921,24)$. 
Betrachters zugeführt worden sind. Ein Mysterium ist diese Technologie des perspektivischen Gemäldes, weil sie das »Göttliche zu einem bloßen Inhalt des menschlichen Bewußtseins zusammenzuziehen scheint, dafür aber umgekehrt das menschliche Bewußtsein zu einem Gefäße des Göttlichen weitet. « ${ }^{17}$ Die ästhetische Bilderfahrung setzte also insofern durchaus Funktionen religiöser Rituale fort, als auch sie eine imaginäre Grenzüberschreitung impliziert. Ich komme später auf diese Gesetze des künstlerischen Bildes und seiner mythischen Erkenntnisform zurück und führe zunächst die Bildbetrachtung zu Ende, um zu einem Résumé zu gelangen.

Klee skelettiert das künstlerische Bild und greift dabei auch, wie schon ausgeführt, die klassisch modernen Techniken an, sofern sie einer kompositorischen Ordnung und damit der althergebrachten Vorstellung, dass die Idee über das Materielle siegt, Geltung verschafften. Niedergelegt war diese idealistische Kunstkonzeption im kanonisierten Verhältnis von formbestimmender Zeichnung (disegno) und attributiver Farbe (colore).$^{18}$ Die Tatsache, dass Klee das lineare Gebilde über der wolkig strukturierten Ölfarbe auftrug, stellt eine Verkehrung jenes hierarchischen Verhältnisses dar, denn die Zeichnung, ihrerseits teilweise buntfarbig, erhebt nicht den Anspruch, eine vorgängige Ordnung zu errichten, die von der Farbe ausgefüllt wird. Vielmehr ist das Verhältnis zwischen der linearen Form und der flächig ausgedehnten Farbe von widersprüchlicher Qualität. Wie schon erwähnt kehren zwar die Farben des Grundes in der anthropomorphen Linienzeichnung wieder, so wie ein Rubens etwa in der Darstellung des Inkarnats die Farben des Raumgrundes sammelte. ${ }^{19}$ Klee revidiert diese altmeisterliche Farbperspektive aber durch die rein lineare Gestalt seiner Hauptfigur, die sozusagen keinen eigenen Körper gewinnt, sondern in der gespenstischen Teilhaberschaft am Grund verbleibt. Auch die vermeintlich klare Relation der Gestirnscheibe zu ihrem violetten schatten lässt sich nicht aufrechterhalten, denn Klee hat diesem eine schrundige Textur gegeben, welche ihn, zumal als Zentrum der oben schon beschriebenen farbigen ‘Glorioles, zum eigenwertigen Formgebilde macht, dem mit gleichem Recht die Gestirnscheibe als Reflex subordiniert werden könnte. ${ }^{20}$

Grenzen des Verstandes ist ein Werk, das hier exemplarisch für eine spezifisch moderne bildkünstlerische Art der Reflexion steht. Um zu zeigen, dass Klee mit seiner satirischen Bildkritik nicht allein steht, möchte ich kurz auf eine formal gänzlich andersgeartete, aber in der Zielrichtung ähnlich gelagerte künstlerische

17 Erwin Panofsky, »Die Perspektive als ssymbolische Form« «, in: Vorträge der Bibliothek Warburg 1924 1925, Leipzig und Berlin 1927, S. 258-330, hier S. 126.

18 Grundsätzliche Erörterungen zur modernen Geschichte dieses Verhältnisses bei Max Imdahl, Farbe. Kunsttheoretische Reflexionen in Frankereich, München 1987.

19 S. hierzu Lorenz Dittmann, Farbgestaltung und Farbtheorie in der abendländischen Malerei. Eine Einführung, Darmstadt 1987, S. $220 \mathrm{ff}$.

20 Diesen Verkehrungen wird eine Beschreibung nicht gerecht, die Klees Bild auf eine dramaturgische Logik verengt. Max Huggler, Paul Klee. Die Malerei als Blick in den Kosmos, Frauenfeld und Stuttgart 1969, S. 108, sah wschwankende Leitern verschwinden im Dunkel des Gestirndampfes.« 
Abb. 8: René Magritte, La condition bumaine, Choisel

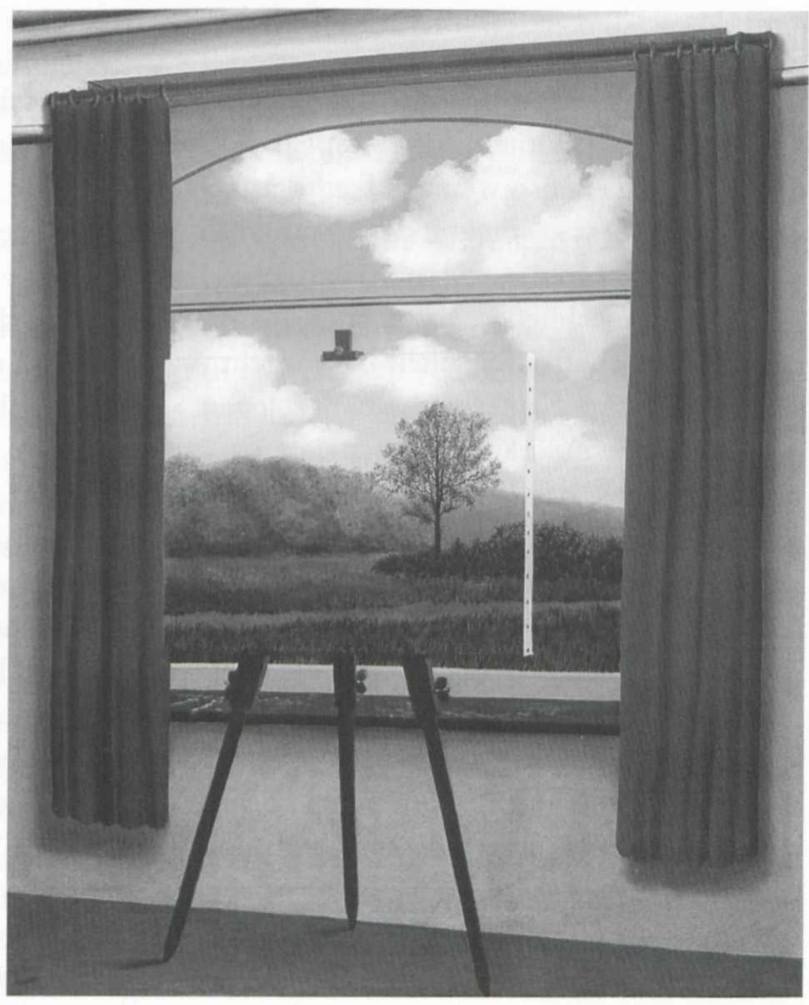

Position verweisen. Auch René Magrittes Thema ist der perspektivische Bildraum und dessen Anspruch auf Evidenz, und obwohl er diesem Anspruch zunächst weit mehr nachkommt als Klee in seiner sperrigen Groteske, unterläuft auch er die dem perspektivischen Raum inhärenten Hierarchien. La condition bumaine (Abb. 8) zeigt dieses Verfahren exemplarisch. Dass der Fensterausblick und das Bild auf der Staffelei die Landschaft aus derselben Perspektive zeigen, kündigt paradoxerweise den Einheitsanspruch der perspektivischen Konstruktion auf, denn diese ist auf eine ontologische Differenz von Figur und Grund, Form und Raum gebaut und wird durch die an ihre Stelle getretene Verdoppelung des Landschaftsausblicks unterminiert. In der pointierten Befragung der traditionellen Aufgabe der Linie, als Grenze zwischen Körper und Freiraum zu fungieren, sind Klees und Magrittes Methoden durchaus verwandt. Der Rand des Bildes auf Magrittes Staffelei ist prinzipiell derselben Identitätskrise unterworfen wie Klees Linien, die ihre Bedeutung als Raumoder Körpergrenze zwar immer wieder behaupten, sie aber ebenso nachdrücklich verwerfen, um zeichenhaften oder abstrakten Qualitäten Platz zu machen. 


\section{Bildtitel und Kunsttheorie}

Die groteske Unterminierung aller kategorialen Unterscheidungen wird auch auf der Ebene des Bildtitels durchgespielt. Klees Formulierung 'Grenzen des Verstandes` lässt sich ebenso wenig auf eine Aussage reduzieren wie die bildliche Darstellung selbst. Dass sie die mit dem Namen Emil du Bois-Reymonds verbundene Debatte über die Grenzen wissenschaftlicher Erkenntnis im 19. Jahrhundert aufruft, ${ }^{21}$ ist nicht auszuschließen, wenn auch aus Klees Schriften die Beschäftigung mit diesem Wissenschaftsstreit nicht hervorgeht. In jedem Fall scheint diese Assoziation keine eindeutige Konsequenz nahezulegen, sondern analog zur visuellen Struktur gegensätzliche Aussagen zu evozieren - auf der einen Seite die Folgerung des Agnostizismus, der Unmöglichkeit von Erkenntnis, auf der andern die Behauptung, dass das Bild an den Grenzen rationaler Erkenntnis eben nicht haltmachen muss, da es potentiell über diese hinausweist. Damit wäre die der ästhetischen Erfahrung seit Baumgarten und Kant eingeschriebene Verheißung ins Spiel gebracht, Erkenntnis jenseits der Schwelle zweckgebundener oder logischer Verstandestätigkeit in der Anschauung wirksam zu machen, nachdem sie durch philosophische Begriffe nicht mehr zum Ganzen synthetisierbar war. Dem Romantiker Friedrich Wilhelm Schelling galt in Fortführung jener Denkansätze die Kunst als »Organon der Philosophie«, als einziger Gegenstand, an dem das Absolute noch erfahrbar werde. Den Weg dahin wies das künstlerische Genie, das nach Schellings Lehre in seiner Arbeit unbewusste Triebkräfte der Natur und bewusste Ideen zusammenführt, so dass in seinem Werk das »Unendliche« aufscheine. Klees Bild ruft durch seine Kosmossymbolik diese Konzeption des `Genieprodukts auf, um sie strukturell in aller Schärfe zu dementieren. ${ }^{22}$

Ein weiterer wissenschaftsgeschichtlicher Kontext liegt nahe: Hat Klee sich im Rahmen seiner zahlreichen perspektivischen Studien einem nicht-euklidischen Raumkonzept zugewandt, dessen vieldimensionale Endlichkeit er im Einklang mit der modernen Physik präsentieren wollte? Weder lässt sich Klees Auseinandersetzung mit der zeitgenössischen Physik belegen, noch spricht die ästhetische Textur seines Werks für eine solche Orientierung und Aussage. Eher überwiegt der Eindruck, dass Klee der metaphysischen Vorstellung eines unendlichen Raums verhaftet blieb und dem gemalten und dem gezeichneten Bild die entsprechende Vermittlerrolle zuwies, so ironisch er auch dieses transzendentale Manöver zerlegte. Klee sah sich durchaus als Erbe der klassisch-neuzeitlichen Kunst und ihrer Raumlogik, was ich mit einer kurzen Notiz zur Kosmosmetaphorik in seinem

21 Hierzu Ferdinando Vidoni, Ignorabimus! Emil du Bois-Reymond und die Debatte über die Grenzen missenschaftlicher Erkenntnis im 19. Jabrbundert, Frankfurt am Main u.a. 1991.

22 Friedrich Wilhelm Joseph Schelling, System des transzendentalen Idealismus (1800), Stuttgart und Augsburg 1856-1861, I/3, S. 327-634 und ders., Über das Verhältnis der bildenden Künste zu der Natur (1807), Stuttgart und Augsburg 1856-1861, I/7, S. 289-329. 
Werk und Schrifttum untermauern möchte. Dabei ist grundsätzlich die verblüffende Tatsache vorwegzunehmen, dass Klee als Autor, das heißt als Interpret seiner Kunst und als Formlehrer am Bauhaus, eine eher unironische Vision entwarf, deren nicht selten pathetische Attitude gegen den kritischen Charakter des zeichnerischen und malerischen Werks absticht. Welches Problem in dieser Aufspaltung von künstlerischer Methode und kunsttheoretischem Argument steckt, lässt sich erahnen, wenn man die Tagebuchnotizen des jungen Italienreisenden Klee liest. Die Begegnung mit der Kultur der Antike und der Renaissance rief große Ratlosigkeit bei ihm hervor. Einerseits sehnte er sich zum »edlen Stik eines Leonardo zurück, ohne die Überzeugung jedoch, mit ihm jemals konform gehen zu können; schließlich bezeichnete er die Satire als einzig mögliche, d.h. zeitgemäße Haltung eines modernen Künstlers. ${ }^{23}$

Die Werkgeschichte belegt, dass Klee als Künstler durchweg seiner frühen Erkenntnis treu blieb, dass nämlich allein Satire die adäquate Haltung sei. Seit dem von ihm als "Opus 1« gewerteten Radierungszyklus der Inventionen ist der Verlust des divinen Individuums und der ihm analogen transzendenten Qualität des Tafelbildes sein Thema. Durchweg leistet Klee seine ironische Reflexionsarbeit dadurch, dass er seine Bildfiguren ihrer autonomen Handlungsgewalt beraubt und sie mit dem Raum verwachsen zeigt.

Die Radierung Der Held mit dem Flïgel $(1905,38)^{24}$ ist mit einer geradezu altmeisterlichen Modellierungstechnik gestaltet. Der tierhaft breitbeinige Stand widerstrebt dem Kontrapost, die Gestalt entwickelt keine eigene Kraft, um sich vom Sockel zu lösen, der eine ihrer Flügel ist verwachsen mit dem Rumpf und entbehrt so der Beweglichkeit. Aufschwnng zu den Sternen $(1912,143)$, schon im pseudokindlichen Kritzelstil gestaltet, radikalisiert diese Idee zur quasi automatistischen Linie, die jeden für den behaupteten Aufschwung notwendigen Willen untergräbt. Agnus Dei qui tollis peccata mundi $(1918,20)$ und Auserwäblter Knabe $(1918,115)$ ergänzen die Thematik um christliche und gewiss auch selbstbildhafte Akzente. ${ }^{25}$ Gelebrter im Umgang mit den Gestirnen (1926) zeigt eine eher philosophische Variante und steht dem Bild Grenzen des Verstandes bereits am nächsten. Die Parallelfiguration vernetzt hier die Figur auf unheimliche Weise mit ihrer Umgebung, einem Baum und seinem Wurzelwerk, einem Motiv, das Klee in seinem Jenaer Vortrag »Über die moderne Kunst« (1924) als Sinnbild des Kunstwerks eingesetzt hat. ${ }^{26}$ Kosmische Symbolik,

23 Klee 1988 (s. Anm. 6), S. 84, Nr. 290 und S. 86, Nr. 294: „Deshalb bin ich wieder ganz Satire. Sollte ich mich noch einmal ganz darin auflösen? Vorläufig ist sie mein einziger Glaube. Vielleicht werde ich nie positiv? Jedenfalls werde ich mich wehren wie eine Bestie.«

24 S. Abb. in Paul Klee, Catalogue Raisonné, hrsg. von der Paul-Klee-Stiftung und dem Kunstmuseum Bern, 9 Bde., Bern 1998-2002.

25 Zur Kunstsymbolik und Passionsthematik dieser Motivgruppe s. Regine Prange, »Hinüberbauen in eine jenseitige Gegend. Paul Klees Lithographie `Der Tod für die Ideer und die Genese der Abstraktion«, in: Walliaf-Richartz-Jahrbuch 54, 1993, S. 281-314.

26 Klee 1924 (s. Anm. 10), S. 71 f. 
kristallin-kubistische Architekturen und organisch-vegetabile Streifenformationen zitieren gleichermaßen den transzendenten Charakter der ästhetischen Raumkonstruktion, ihre vermeintliche Kraft zur unmittelbaren Präsentierung einer höchsten Idee. Durch die Verflechtung von Figur und Grund wird diesem metaphysischen Anspruch jedoch das Fundament entzogen.

In Klees theoretischen Überlegungen, die er in einer ersten programmatischen Schrift für den Sammelband Schöpferische Konfession niedergeschrieben hat, findet man diesen ironischen Umgang mit der welthaften Attitude des Kunstwerks nicht wieder. Hier wird die Einheit von Natur und Kunst beschworen und mit der Verklärung der Kunst zum Schöpfungsgleichnis ${ }^{27}$ nun indirekt doch die Ebenbürtigkeit mit den Künstlerautoritäten der Renaissance postuliert. Insbesondere Leonardo war es, der die Malerei als Spiegel des Universums gedeutet und ihr dadurch einen unüberbietbaren intellektuellen Rang zugewiesen hatte. Für die umstrittenen Avantgardekünstler des frühen 20. Jahrhunderts, die ihr bürgerliches Publikum zufriedenstellen wollten, schien dieses vielfach immer noch das einzig vertretbare Konzept zu sein, auch wenn sie in ihrer Kunst de facto zum Angriff auf die neuzeitliche Tradition übergegangen waren. Die historische Differenz wird aber im Funktionswandel der Theorie greifbar. Wo Leonardo aus seiner naturwissenschaftlichen Durchdringung der Malerei ihren Rang zu steigern suchte, betonte Klee, ganz dem Geiste der idealistischen Ästhetik verpflichtet, jene Anteile der Kunstproduktion, die durch rationale Wissenschaft nicht erreicht werden können. ${ }^{28}$ Mit der Ausblendung der satirischen Negation geht also der Hinweis auf die Beschränktheit des Wissens einher. Die graphische Linie verwirklicht demnach das der Kunst schlechthin eingeborene Ziel, ein unsichtbares und unerforschliches Wesen sichtbar zu machen. Der Künstler überhöht den Zeichenprozess, indem er ihm alle konstruktiv artifiziellen Aspekte nimmt und ihn als eine naturhafte Bewegung, als Werden, ja als Genesis beschreibt. Diese schöpferische zeichnerische Bewegung nennt Klee »eine kleine Reise ins Land der besseren Erkenntnis. ( $^{29}$ Seine Kritik der Perspektive will er nicht als solche verstanden wissen, sondern als Überwindung künstlicher Statik durch das Prinzip des Lebendigen selbst: »Über den toten Punkt hinweggesetzt sei die erste bewegliche Tat (Linie). $\ll^{30}$ Der Werk-

27 Paul Klee, »Beitrag für den Sammelband von Kasimir Edschmid, Schöpferische Konfession«, Berlin 1920, verfasst 1918, in: Regel 1995 (s. Anm. 10), S. 60-66, hier S. 64f.: »Aus abstrakten Formelementen wird über ihre Vereinigung zu konkreten Wesen oder zu abstrakten Dingen wie Zahlen und Buchstaben hinaus zum Schluß ein formaler Kosmos geschaffen, der mit der großen Schöpfung solche Ähnlichkeit aufweist, daß ein Hauch genügt, den Ausdruck des Religiösen, die Religion zur Tat werden zu lassen. $[\ldots]$ Kunst verhält sich zur Schöpfung gleichnisartig.«

28 »Im obersten Kreis steht hinter der Vieldeutigkeit ein letztes Geheimnis, und das Licht des Intellekts erlischt kläglich. [...] Die Kunst spielt mit den letzten Dingen ein unwissend Spiel und erreicht sie doch!« Ebd., S. 65f.

29 Ebd., S. 61.

30 Ebd. 


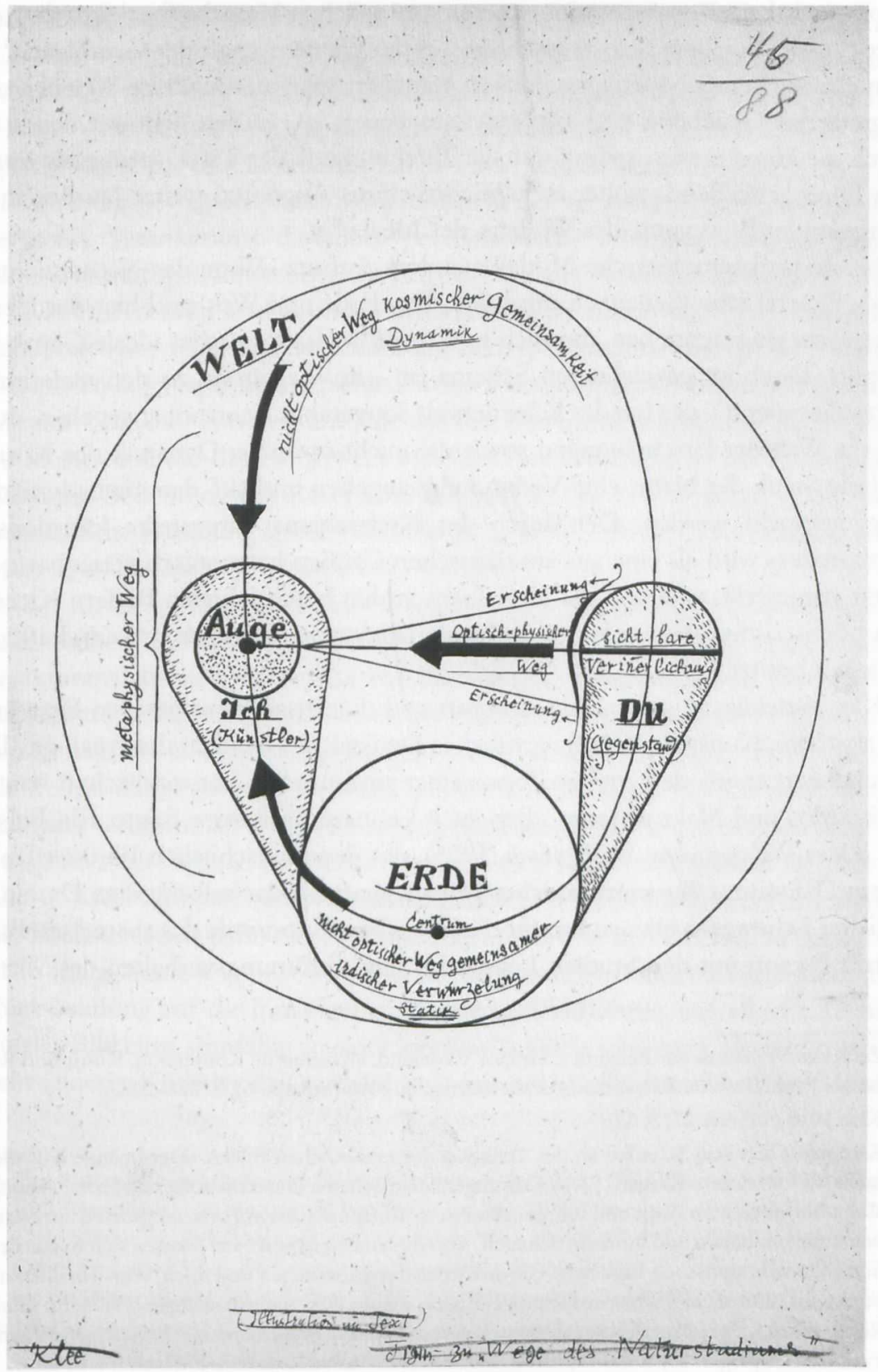

Abb. 9: Paul Klee, Schema Ich - Du - Erde - Welt, Feder auf Papier, Paul Klee Stiftung Pädagogischer Nachlass (vgl. Farbtafel 38) 
prozess wird zur Repräsentation einer ursprünglichen Naturkraft erklärt, die, trotz Klees ausdrücklichem Selbstausschluss aus der Gemeinschaft der Gläubigen ${ }^{31}$ mit dem christlichen Schöpfungsgedanken assoziiert scheint: »Auch im Weltall ist Bewegung das Gegebene [...] Ein gewisses Feuer, zu werden, lebt auf, leitet sich durch die Hand weiter, strömt auf die Tafel und auf der Tafel, springt als Funke, den Kreis schließend, woher es kam: zurück ins Auge und weiter [zurück in ein Zentrum der Bewegung, des Wollens, der Idee]. $\aleph^{32}$

Noch das kosmologische Modell aus dem Aufsatz »Wege des Naturstudiums« (Abb. 9) setzt jene Gedanken um. ${ }^{33}$ Ich, Du, Erde und Welt sind hier der idealen Kreisform eingeschrieben, die auch in Grenzen des Verstandes das ideale Ganze verkörpert. Doch im gezeichneten Schema ist - im Gegensatz zu den malerischen Formulierungen - das Ich des Künstlers als souveränes Zentrum angegeben, durch das die Welt der Erscheinungen sowie die micht-optischer Dynamik des Kosmos und die Statik der Natur eine Verbindung eingehen und auf den smetaphysischen Weg` gebracht werden. Der durch das Kreisschema dargestellte künstlerische Werkprozess wird als eine aus antithetischen Größen harmonisch vereinbarte Totalität vorgestellt, während die Kreisform in den beschriebenen Bildern Klees einen höchst ambivalenten Status als idealer Zielort künstlerisch-wissenschaftlicher Tätigkeit besitzt.

Klee verteidigt in seinen theoretischen und didaktisch-konzeptuellen Entwürfen die abstrakte Kunst als nicht-begriffliches Denken, ein Denken der Analogie. Darin rekurriert er auf den antiken Topos einer strukturellen Verwandtschaft von Mikrokosmos und Makrokosmos, dem auch Leonardo zeitweise folgte. Ein Beispiel aus Klees Pädagogischem Skizzenbuch (1925), das den menschlichen Blutkreislauf in einem Diagramm illustriert, welches gleichnishaft für das selbständige Dasein natürlicher Lebewesen ebenso wie für die lebendige Autonomie des abstrakten Bildes eintritt, ${ }^{34}$ kann mit den Studien Leonardos zum Strömungsverhalten des Wassers

31 Zu Klees Verhältnis zur Religion s. Gregor Wedekind, „Kosmische Konfession. Kunst und Religion bei Paul Klee«, in: Bätschmann und Helfenstein 2000 (s. Anm. 6), S. 226-238.

32 Klee 1918 (s. Anm. 27, S. 63).

33 Klee misst hier sein Schaffen an der Tradition des mimetischen Bildes: »Der heutige Künstler ist mehr als verfeinerte Kamera [...]. Das abgebildete Schema illustriert folgenden Satz: »Sämtliche Wege treffen sich im Auge und führen, von ihrem Treffpunkt aus in Form umgesetzt, zur Synthese von äußerem Sehen und innerem Schauen. Von diesem Treffpunkt aus formen sich manuelle Gebilde, die vom optischen Bild eines Gegenstandes total abweichen und doch, vom Totalitätsstandpunkt aus, ihm nicht widersprechen.« Paul Klee, »Wege des Naturstudiums« [1923], in: Günther Regel (Hrsg.), Paul Klee. Kunst-Lehre. Aufsätze, Vorträge, Rezensionen und Beiträge zur bildnerischen Formlehre, Leipzig 1987, S. 67-70, hier S. 69 f.

34 Paul Klee, Das pädagogische Skizzenbuch (Erstausgabe 1925), Mainz und Berlin 1965, S. 22. Der kommentierende Text verdeutlicht die Analogie zum kosmologischen Modell des künstlerischen Sehens (Abb. 9, Anm. 34). „I Das Herz pumpt (aktiv). III Das Blut wird bewegt (passiv). II Die Lunge empfängt und gibt verändert weiter, beteiligt sich (medial). I Das Herz pumpt. III Das Blut wird von neuem in Bewegung gesetzt und kehrt zum Herzen, seinem Ausgangspunkt, zurück.«- 
verglichen werden, dem ebenfalls eine zentrale kunstsymbolische Rolle zukam. ${ }^{35}$ Leonardo verglich etwa den Wasserkreislauf der Erde mit dem Blutkreislauf des Menschen, die Form von Wasserstrudeln mit Lockenwindungen des menschlichen Haars $^{36}$ - Strukturanalogien, die auch in seinen Bildern aufzufinden sind. Der Vergleich von Klees und Leonardos Einsatz von Wasser beziehungsweise Blut als Paradigma der bewegten Natur hat überdies in der verwandten Intention der Künstler seine Verankerung, die starre perspektivische Raumkonstruktion zugunsten einer wahrhaftigen künstlerischen Antwort auf die »Welt als Fluss « zu revidieren. ${ }^{37}$

Die Differenzen sind dennoch offenkundig. Sie lassen sich schon daran ermessen, dass Klee nicht eigene Forschung betreibt, sondern eine große Vielfalt von Beispielen aus Natur und verschiedensten lebensweltlichen Bereichen (auch Technik und Sprache) einsetzt, um jene aus der Bewegung abgeleitete ideelle Totalität zu illustrieren, die das Kunstwerk erreichen soll. Auffällig ist bei Klee außerdem die hohe Bedeutung der Rezeption, die erst für das Ganze sorgt. „Das Werk als menschliche Handlung (genesis) ist, sowohl produktiv als rezeptiv: Bewegung [...] Das Auge begeht die ihm im Werk eingerichteten Wege. ${ }^{38}$

Wo für Leonardo Kunst und Wissenschaft in einem organischen Zusammenhang stehen und dem repräsentativen Ziel der Kunst dienen, benutzt Klee die strukturanalytischen Vergleiche zwischen Natur, Lebenswelt und Kunst zur Verschleierung seiner kritischen Arbeit am Bild. Als Künstler konnte es ihm wie anderen Protagonisten der Avantgarde nicht mehr um die Errichtung von Kunstwerken als Weltmodellen gehen, auch wenn sein Selbstbewusstsein wie das vieler moderner Künstler weiterhin an diese Anmaßung gebunden scheint. Zu trennen ist insofern zwischen dem Denken des Künstlers über seine Kunst und seinem Denken in der Kunst. Klees `künstlerischer Gedanke gilt nicht der anschaulichen Präsentation einer höchsten Idee, denn diese repräsentative Kraft besitzt das Bild in der Moderne nicht mehr. Seine kognitive Kompetenz liegt vielmehr in der kritisch-destruktiven Rückwendung auf die ihm eigenen Regeln und Verfahren, auf all jene Techniken, die das Bild einst sinnfällig zu einer ideellen Totalität schlossen. Dass Leonardo wie kein anderer Künstler den »edle[n] Stik mit der »Vollkommenheit der Mittek zur

Zur Autonomie des abstrakten Bildes: Klee hatte sich schon 1912 Delaunay zum Vorbild gewählt, weil dieser, anders als die analytischen Kubisten, »den Typus eines selbständigen Bildes schuf, das ohne Motive aus der Natur ein ganz abstraktes Formdasein führt. Ein Gebilde von plastischem Leben [...].«Paul Klee, «Rezension zur Ausstellung des Modernen Bundes im Kunsthaus Zürich» in: Die Alpen, 12, 1912 (S. 696-704), S. 53, Wiederabdruck in: Regel 1995 (s. Anm. 10), S. 50-57.

35 Hierzu Frank Fehrenbach, Licht und Wasser. Zur Dynamik naturphilosophischer Leitbilder im Werk Leonardo da Vincis, Tübingen und Berlin 1997, S. 193ff., Abb. 97-102.

36 Leonardo da Vinci, Sämtliche Gemälde und die Schriften zur Malerei, hrsg., komm. und eingel. von André Chastel, München 1990, S. $320 \mathrm{f}$.

37 Entsprechend sieht Fehrenbach 1997 (s. Anm. 35), S. 14, in Leonardos Thematisierung der Natur als offenen Prozesses den »Übergang zum Produktionspathos »moderner< Kunst» hergestellt.

38 Klee 1925 (s. Anm. 34), S. 23. 
Deckung gebracht habe, notierte Klee auf seiner Romreise, noch eingedenk der unüberbrückbaren historischen Distanz.

\section{Die Raumgrenze. Kurzer Exkurs zur Selbstbezüglichkeit des Bildes}

Um die Differenz des modernen gegenüber dem klassischen neuzeitlichen Tafelbild in den Blick zu bekommen, bedarf es der Einsicht in eine historische Kontinuität: Das ästhetische Bild definiert sich in all seinen Stadien als ein Ganzes. Es schließt sich in einen Rahmen ein, der seine Totalität begründet und daher auch im Bild selbst indiziert werden muss. Mit anderen Worten: Schon das frühneuzeitliche Kunstbild muss auf sein eigenes Bildsein verweisen, um als Totalität erfahrbar zu sein. Die Selbstbezüglichkeit des Bildes ist per se kein modernes Phänomen, sondern ein notwendiges Moment des ästhetischen Bildes. Neuere Forschungen zur Metapicturalität des traditionellen Kunstbildes haben diese Dimension erschlossen. ${ }^{39}$ Bislang weitgehend übersehen wurde jedoch die radikale Veränderung jener Selbstbezüglichkeit des Bildes in der Moderne. ${ }^{40}$ Während das neuzeitliche Tafelbild seine Grenze in einer Weise thematisiert, die den fiktionalen Schein bekräftigt und intensiviert, ist die moderne Selbstbezüglichkeit des Bildes, wie bei Klee ausführlich dargestellt, eine kritische, den Schein zerstörende Operation. Bevor diese Differenz im Bildvergleich konkret erschlossen werden soll, muss noch einmal grundsätzlich auf die historische Konstituierung des Bildraums bzw. der ästhetischen Grenze eingegangen werden.

Es ist daran zu erinnern, dass die Erkenntnisfunktion von Bildern in der mittelalterlichen Tradition durch die Unterdrückung von räumlichen Wirkungen zugunsten ihrer Zeichenhaftigkeit gestärkt worden ist, gemäß platonischer Denktradition, die den mimetischen Potentialen nicht zutraute, zum geistigen Wesenskern der Dinge vorstoßen zu können. In der christlich-abendländischen Kultur musste bildliche Repräsentation permanent gegen den Vorwurf in Schutz genommen werden, dass sie allein der sinnlichen Lust diene. Den geistigen Charakter der Bilder sicherte daher stets eine Einschränkung ihres Abbildcharakters. Illusionistische Darstellungsstrukturen wurden im Mittelalter ihrer Funktion entkleidet und zu zeichenhaften Formeln abstrahiert. Wichtig war es, den religiösen Bildinhalt oder die Identität einer heiligen Person eindeutig erkennen zu können, so dass das ikonische Bildparadigma zu Recht durch eine Annäherung des Bildes an die Schrift gekennzeichnet worden ist. ${ }^{41}$

39 U.a. Victor I. Stoichita, Linstauration du tableau, Paris 1993, dt. Das selbstbewusste Bild. Vom Ursprung der Metamalerei, München 1998. Klaus Krüger, Das Bild als Schleier des Unsicbtbaren. Ästhetische Illusion in der Kunst der früben Neuzeit in Italien, München 2001.

40 Diese spezifisch wikonoklastische« Selbstbezüglichkeit des modernen Bildes thematisiert Prange 2006 (s. Anm. 3). Die semiotisch orientierte Bildwissenschaft geht hingegen von einer universalen Qualität bildlicher Selbstbezüglichkeit aus. Siehe z.B. William J. Thomas Mitchell, Picture Theory, Chicago und London 1994, S. $35 \mathrm{ff}$.

41 Daniel Spanke, Porträt, Ikone, Kunst, München 2004. 
Auch für das sich seit Giottos Neuerungen etablierende Kunstbild gilt jedoch der Vorbehalt gegen die Nachahmung, obwohl es durch den Rekurs auf die Antike begann, sich klerikalen Interessen und religiösen Dogmen zu entwinden. Durch die neuplatonische idea-Lehre wurde nun in der Kunsttheorie der Anspruch erhoben, dass das Bild als solches, als eine in sich geschlossene Entität, die Idee des Göttlichen vermittle. Der Künstler trat als Mediator gleichsam in den Rang des Priesters, wenn nicht des göttlichen Weltbaumeisters selbst; er bewerkstelligte die Transsubstantiation mit den Mitteln seiner malerischen Technik und Erfindungskraft. ${ }^{42}$ Dieser Schöpfungsmythos ist nicht nur ein Topos der Kunsttheorie, er wird getragen von der strukturellen Natur des neuen künstlerischen Bildes, auf die ich eingangs schon hingewiesen habe.

Den kultischen Raum ergänzt und ersetzt der konstruierte Scheinraum, in dem die religiösen Zeichen in sinnliche Evidenz aufgehoben werden und die Empfindung von unmittelbarer Präsenz des Dargestellten in Zeit und Raum aufgerufen wird. Der Bildraum als künstlerisch hergestellter Mikrokosmos bürgt für die Wahrhaftigkeit der bildlichen Darstellung, und zwar nicht durch die bloße Befolgung perspektivischer Gesetze, sondern dadurch, dass eine sowohl hermetische also auch überschreitbare Grenze definiert wird. Erst die Definition einer solchen imaginären Grenze begründet die Autonomie und Vollständigkeit des ästhetischen Bildes. Im Quattrocento tritt in diese Funktion vor allem die gemalte Architektur ein, deren Rahmen- und Nischenformation etwa in Masaccios Trinität eingesetzt wird, um die ästhetische Grenze zu markieren. Maria als Vermittlerfigur verstärkt die imaginäre Begehbarkeit des Bildraums und somit die anschauliche Partizipation an seinem ideellen Gehalt.

Das flächige vorästhetische Bild hat dagegen keine selbstbezügliche Struktur. Es definiert sich als Statthalter des bezeichneten Göttlichen, was sich in den Legenden der snicht von Hand gemachten Kultbilder (sog. archeiropoeita) abbildet. ${ }^{43}$ Sein Raum ist nicht selbstgestiftet, es ist der vom Kult geschaffene sakrale Handlungsraum, dessen Rahmen nicht durch eine ästhetische Grenze konstituiert wird, sondern durch rituell ausgeführte Schwelleninszenierungen, zum Beispiel Prozessionen. Was bedeutet dies für den kognitiven Status des Bildes im Zuge seiner Ästhetisierung? Eine eigentümliche Umkehrung findet statt. Während das sakrale Bild bemüht ist, durch eine starke Konventionalisierung der ikonographischen Formeln die denotative Verweisfunktion und mithin die sofortige Erkennbarkeit des Inhalts zu fördern, seine Zeichenfunktion also offen vorweist, geht das künstlerische Bild umgekehrt vor. Es verstärkt die konnotativen Aspekte, um mög-

42 Zur Begriffsgeschichte der »idea« s. Panofsky 1924/1925 (s. Anm. 17). Bestes Beispiel ist der berühmte Brief Raffaels an Castiglione, in dem er von seiner Fähigkeit berichtet, mittels einer »gewissen Idee« aus unvollkommenen Frauenkörpern vollkommene Schönheit destillieren zu können. S. ebd., S. $32 \mathrm{f}$.

43 Hans Belting, Bild und Kult. Eine Geschichte des Bildes vor dem Zeitalter der Kunst, München 1993, S. 64ff. 
lichst alle Eindeutigkeit aufzuheben. ${ }^{44}$ Seine Intellektualität manifestiert sich gerade durch die Verschleierung kodifizierter Bedeutungen, wofür Leonardos verführerisch-engelhafter Johannes (Abb. 1) ein besonders imponierendes Beispiel ist.

Das neue künstlerische Bild sichert seine Grenze und damit seine Wahrheit, indem es zwei gegensätzliche Bewegungen miteinander vereint. Einerseits präsentiert es sich als hermetisch in sich geschlossene eigene Wirklichkeit, zum andern adressiert es den Betrachter, etwa durch den Blick aus dem Bild oder durch die Appellation an seine libidinösen Bedürfnisse nicht zuletzt dadurch, dass der Akt und seine sexuelle Faszination zur zentralen Bildaufgabe gemacht werden.

Zu den Paradoxien des künstlerischen Bildes gehört, dass es sich, zur Erzeugung des sinnlichen Scheins, wissenschaftlicher Erkenntnisse der Optik und der Geometrie bedient. Rationale Methoden werden absorbiert, um sie der Konstruktion von Präsenz, der imaginären Augenzeugenschaft zumeist transempirischer Ereignisse wie der christlichen Heilsgeschichte oder mythologischer Szenen dienstbar zu machen. Bedeutung wird nicht mehr primär durch die Präsentation kollektiv dechiffrierbarer Zeichen erschlossen, vielmehr werden diese in die lustvolle, individuelle Erfahrung der Bildbetrachter unmerklich eingeschrieben. Der Linearperspektive und allen anderen ergänzenden Konstruktionsmethoden (Luft- und Farbperspektive, Sfumato, Helldunkel usw.) kam die Rolle zu, einen autonomen Bildraum zu simulieren, der den Betrachtern die imaginäre Teilhabe an den dargestellten Szenen und ihrem Heilsgehalt ermöglicht. Der visuell inszenierte Akt der Einfühlung gilt also dem Übergang in eine ideale Wirklichkeit. Das ästhetische Bild ist durch sein individualisiertes Transzendenzangebot zu charakterisieren, das als ein persönlich produziertes und rezipiertes über eine bestimmte Gottesidee hinausweist. Gleichwohl ging mit dem Ende der verbindlichen christlichen Ikonographie auch die Vereinbarkeit von Idee und Anschauung im malerischen Bildraum verloren. Die Malerei verlor, so der Tenor zahlreicher Kritiken des 19. Jahrhunderts, ihren idealen Gehalt, wovon die Zersetzung des perspektivischen Einheitsraums Zeugnis ablegte. ${ }^{45}$ Sie wurde subjektivistisch und im gleichen Maße abstrakt; ihr geistiger Gehalt schien in Frage gestellt. Dieser bis weit ins 20. Jahrhundert noch wirksame Vorwurf erklärt in gewisser Weise, warum Klee sich der alten idealistischen Formeln meinte bedienen zu müssen, um seiner Kunst Geltung zu verschaffen, und nicht offen die Position der Satire verfocht.

\section{Klee und Leonardo. Ein Bildvergleich}

Klees Kunst ist anders als seine Kunsttheorie von der Einsicht getragen, dass der direkte, Begriff und Anschauung einende Zugriff auf das Ganze und Wahre nicht

44 Vgl. Norman Bryson, Das Sehen und die Malerei. Die Logik des Blicks, München 2001, S. 88ff. zu Denotation und Konnotation in der Malerei.

45 Hierzu Prange 2006 (s. Anm. 3). 
(mehr) möglich ist. Die kognitive Qualität seiner Bilder liegt nicht mehr in der Repräsentation, sondern in der Repräsentationskritik. In der satirischen Dekonstruktion des Bildraums wird jene auratische Mehrdeutigkeit des traditionellen Tafelbilds thematisiert und seziert, für die exemplarisch Leonardo und seine innovative Bildraumgestaltung angeführt werden können. Der Vergleich drängt sich schon dadurch auf, dass Leonardos Leitidee einer aus dem Fluss der Elemente gewonnenen Totalität, wie oben ausgeführt, auch in Klees Formlehre eingegangen ist. Dies bedeutet freilich nicht, dass letzterer sich als Künstler Leonardo zum Vorbild genommen und sein Johannes der Täufer (Abb. 1) als Vorlage für Grenzen des Verstandes (Farbtafel 44) gedient hätte. Leonardos Werk bringt vielmehr wesentliche Strategien des Kunstbildes zur Entfaltung, auf die Klee generell mit seiner künstlerischen Arbeit reagiert hat. Allein darin ist die partielle Strukturverwandtschaft der Bilder begründet, um die es im Folgenden gehen wird.

In beiden Werken ist die Beziehung des Menschen auf eine höhere Wahrheit thematisch. Klees Himmelsleiter entspricht des Johannes' machtvoller Zeigegestus mit der Rechten, der das Oben im Bild bzw. den jenseits des Rahmens scheinbar fortsetzbaren Raum als Sphäre des christlichen Himmels bestimmt. Adressat dieser Geste ist, wie der informierte Betrachter aufgrund des Tierfells weiß, welches den Täufer identifiziert, das von Christus in Gang gesetzte Heilswerk, dessen Licht auf seinen Verkünder abstrahlt. ${ }^{46}$ Diese Verweisebene sichert dem Bild im Kontext einer noch religiös gebundenen Kultur objektiven Erkenntniswert. Seine Überzeugungskraft als Kunstbild gewinnt es jedoch keineswegs durch die rudimentären Sinnzeichen, sondern durch den Schein subjektiver Innerlichkeit. Der einladend liebreiche Blick verbunden mit lebhafter Gestik bringt die Figur in einen fiktiven Dialog mit dem Betrachter. Das leuchtende Inkarnat entfacht sinnliches Interesse, das gleichwohl transformiert und auf den Weg des christlichen Mysteriums weitergeleitet wird. Diese Verbindung des Subjektiv-Erotischen mit dem Transzendenten leistet Leonardo durch eine metapicturale Architektur seines Bilds, anders gesagt durch eine durchgängige Thematisierung und Ausdeutung seiner Schwellenlage zwischen einem Innen und einem ‘Außen ${ }^{47}$ Durch das zentrale Motiv des Blicks aus dem Bild thematisiert das Gemälde die ästhetische Grenze. Zugleich verknüpft es die Adressierung des Realraums svor dem Bild mit der Referenz auf einen transzendenten Raum jjenseitsı des Bildes. Das Lächeln gilt nicht nur dem Betrachter, sondern ist Träger des Wissens um das Göttliche, das im Bild selbst nicht anwesend sein kann und doch

46 Joh. 1, 6-8: „Ein Mann trat auf, gesandt von Gott, sein Name war Johannes. Dieser kam zum Zeugnis, dass er zeuge von dem Lichte, damit alle zum Glauben kämen durch ihn. Nicht war er selber das Licht, sondern zeugen sollte er vom Lichte. « Auf diese Stelle bezieht Paul Barolsky, "The Mysterious Meaning of Leonardo's Saint John the Baptist«, in: Source 8, 3, 1989, S. 11-15, das Bild.

47 Zu selbstreflexiven Aspekten der Johannestafel Leonardos vgl. Krüger 2001 (s. Anm. 39), S. $125 \mathrm{ff}$. Man könnte darüber hinausgehend die Überlegung anstellen, dass in dieser Bildstruktur das westliche Konzept des Individuums konstituiert wird, welches seine Existenz in einem psychischen Innen mit einem hiervon abgespaltenen Blick von sAußen vereint. 
von ihm repräsentiert wird. Die Rolle des Johannes, der als Zeuge des Messias für dessen wahre Existenz bürgt und sich doch, als Garant der göttlichen Natur Christi, selbst verneinen muss, um diese Garantie zu erbringen, ${ }^{48}$ wird von Leonardo als Gleichnis für die Funktionen des künstlerischen Bildes und seiner repräsentativen Rolle behandelt. So wie Johannes auf sich selbst verweist und diesen Gestus zugleich durchkreuzt mit der Rechten, die dem unsichtbaren Gott gilt, verweist das Kunstbild auf sich mit der paradoxen Intention der Selbstverneinung, um seine sZeugenschaft, die Echtheit der von ihm repräsentierten Welt zu dokumentieren.

Alle Elemente in Leonardos Täuferbild sind in diesem kunstsymbolischen Sinn doppelt kodiert. Das von außen einfallende Licht ist einerseits mit dem Erfahrungsraum des Betrachters liiert - das plastische Relief stärkt seine imaginäre Augenzeugenschaft, den Eindruck der Überschreitbarkeit der ästhetischen Grenze. Andererseits verweist das Licht auf ein Abwesendes - die jenseits des Bildfelds lokalisierte göttliche Quelle, auf die Johannes mit seiner Rechten zeigt. Doppeldeutig ist auch der dunkle Bildgrund, der einen geschlossenen inneren Raum schafft, ihn zugleich aber als potentiell unendlichen, ungreifbaren inszeniert, nicht zuletzt durch das Sfumato der Täufergestalt, deren Verhältnis zum Raum unbestimmt bleibt. Ebenso komplex ist die Torsion der Figur. Sie scheint sich aus eigenem Impuls heraus an den Betrachter zu wenden, um ihn durch die sich überlagernden Gesten vom endlichen eigenen Leib zur unendlichen Wahrheit des Christentums zu führen. Vor allem die Dezentriertheit des geneigten Kopfs und die übergroße rechte Hand mit dem energisch und steil gerichteten Zeigefinger verhindern, dass die körperliche Attraktivität allein genossen, sondern vielmehr der leere Raum zum Zielort des Schauens wird.

Vergleicht man Leonardos Johannestafel mit Masaccios Trinität, die Maria als Vermittlerin zwischen Betrachter und Bildraum einsetzt, wird die enorme Verdichtungsarbeit deutlich. Hatte das frühe Quattrocento die Inszenierung der ästhetischen Grenze vor allem an die Rahmen und Schwellen der Bildarchitektur geknüpft, ${ }^{49}$ verschweißt Leonardo die konträren Bewegungen aus dem Bild heraus und ins Bild hinein in einer einzigen Halbfigur. Damit wird die Vergegenständlichung der Bildgrenze im Bild nicht etwa hinfällig. Leonardo formiert sie in der Figur selbst und kann auf diese Weise die schon von Masaccios oder Mantegnas Rahmenarchitekturen intendierte fiktive Entgrenzung radikalisieren. Die innerhalb des Bildraums verkörperte Grenze ist als solche sinnfälliger Übergang: Der angewinkelte Arm des Johannes schrankt ihn gegen den Betrachter ab, setzt die Bildgrenze neu und interpretiert sie

48 »Ich bin nicht der Christus! (Joh. 1, 20) »Nach mir kommt einer, der mir voraus ist, weil er eher war als ich.« (Joh. 1, 30) »Und ich habe gesehen und habe bezeugt: dieser ist der Sohn Gottes.« (Joh. 1, 34).

49 S. Felix Thürlemann, »Andrea Mantegna - Der San Zeno-Altar. Selbstreflexion der Mimesis« in: Vom Bild zum Raum. Beiträge zu einer semiotischen Kunstwissenschaft, Köln 1990, (S. 91-108); Louis Marin, Das Opake der Malerei. Zur Repräsentation im Quattrocento, Berlin 2004. 
als eine Schwellenformation, die sinnliche Erfahrung über sich hinausführt in religiöse Vorstellung.

Diese Beobachtungen sollten gezeigt haben, dass die Selbstreferenz des Mediums auf der Ebene der Renaissancemalerei keine kritische, sondern eine affirmative ist. Sie dient der Negation des Mediums oder, anders gesagt, seinem illusionistischen Charakter. Wenn Leonardo auf eine zuvor nicht dagewesene Weise den Präsenzeindruck seiner Bildfigur steigerte, untermauerte er den Anspruch des mimetischen Bildes, über sich selbst hinaus auf eine immaterielle Totalität der Idee verweisen zu können. Sein Johannes ist - was paradox anmutet - ein autonomer Vermittler und spiegelt als solcher die dialektische Struktur des Tafelbilds, das Anwesenheit und Abwesenheit, Anschauung und Begriff durch die Konstruktion ästhetischer Erfahrung als einer Übergangserfahrung zusammenzuschließen vermochte. Nicht außer acht zu lassen ist dabei das imitative Paradigma des neuzeitlichen Tafelbildes, das dieses vom kodifizierten Bilddenken des Mittelalters unterscheidet. Das neuzeitliche Ideal der Naturnachahmung steht nicht etwa im Gegensatz zur Beobachtung bildlicher Selbstreferentialität, sondern begründet diese. Da das Erkennen über das Sehen stimuliert und organisiert wird, muss dem Betrachter ein imaginärer Zutritt zur Bildwelt ermöglicht werden, die Begrenzung des Bildes als Schwellenraum begehbar werden. Hier berühren sich Fläche und Raum, wie an der rahmenden Armbeuge des Johannes ausgeführt worden ist. In einem noch umfassenderen Sinn ist Leonardos Sfumato-Technik auf diese imaginäre Grenze des Bildes zu beziehen. Indem sie für eine Verwischung der Konturen und damit der Gegenstandsgrenzen sorgt, vereint sie alle räumlich differenten Bildebenen in einer letztlich flächigen Textur. Auf der andern Seite verschleiert die atmosphärische Farbabschwächung den Werkprozess als Konstruktion, um die Normalität der optischen Wahrnehmung noch besser zu imitieren. Die vibrierende, den Zeit-Raum zwischen dem Noch-nicht- oder Nichtmehr-Gesehenen eröffnende Kontur verheißt - metapictural - den Triumph der Malerei über die Vergänglichkeit. Sie selbst präsentiert sich als das Medium, welches sich durch die Gestaltung der Veränderlichkeit und Geschichtlichkeit als metaphysisches Prinzip begreift. ${ }^{50}$

Klee stellt hingegen die Stofflichkeit seines Bildes aus, sowohl die des Bildträgers als auch die der Farbe. Die Zeichnung wird nicht als Unterzeichnung oder Vorzeichnung aus dem Bereich des vollendeten Gemäldes herausgenommen, sondern beansprucht volle Sichtbarkeit. Vornehmlich im Medium der Zeichnung inszeniert aber auch Klee - durch die dialektische Kraft seiner Linie - die ästhetische Grenze. Darin zeigt sich, dass Klees Bildkunst, obwohl sie längst nicht mehr dem Paradigma der Naturnachahmung unterstellt werden kann, dennoch in einen historischen Kontext mit der neuzeitlichen Ölmalerei gestellt werden muss. Klees Linienführung lässt sich als eine andere - ikonoklastische - Form des Sfumato

$50 \mathrm{Zu}$ Leonardos Auffassung des bewegten Sehens und seiner Konzeption eines verzeitlichten Bildes siehe Fehrenbach 1997 (s. Anm. 35), S. 169 ff. 
begreifen, denn bei all ihrer Präzision, die jener malerischen Technik diametral entgegengesetzt scheint, ist auch ihr Ziel die Auflösung der Kontur, ja jeder fixen Identität. Gleichwohl ist dieser Schwebezustand keiner, der die anschauliche Präsenz der Bildfigur steigern und den imaginären Eintritt der Betrachter in eine ideale Bildwelt fördern würde. Wo Leonardos Kunst von der Medialität des Bildes ablenkt, um eine direkte Begegnung mit dem christlichen Mysterium zu inszenieren, macht Klee den ^Apparat^ der Kunst präsent. Es gibt kein räumliches `off^, um es in der Terminologie der Filmwissenschaft auszudrücken; mit dem Gestirn wird dieses transzendente Ziel in das Bildfeld hineingezogen. Wo Leonardo höchste Erkenntnis mit lustvoller Anschauung verbindet, entzieht Klee seinem Bild jede klare Sinnaussage und verursacht somit eher die unheimliche Wirkung der Groteske. Sie resultiert daraus, dass sich der technoide Aufbau mit organischer Belebtheit verbindet. Alle konstruktiven Operationen - das Aufwärtsstreben, die Transparenz, Schichtung und Staffelung im Raum - werden an eine rudimentäre Bildfigur, mithin an eine subjektive vitale Größe gebunden. Wenn auch der sinnlich-erotische Appell an die Betrachter unterbleibt, ist bei Klee wie bei Leonardo der Blick aus dem Bild explizit Thema. Im Vergleich lässt sich zeigen, wie Klee dieses zentrale Motiv neuzeitlicher Historien- und Genremalerei analysiert und dadurch den metaphysischen Kern des Tafelbildes ironisch dementiert.

Erinnern wir uns zurück an Masaccios Maria, deren Position, Blick und Gestik jene eigentlich unmögliche Vermittlung zwischen einer sautonomen Bildwelt und dem realen Betrachterraum leistet, indem sie die Überschreitbarkeit der ästhetischen Grenze suggeriert. Leonardos Johannes (Abb. 1) entfaltet diese Vermittlerfigur, indem er sie verselbständigt und dadurch den Selbst- und Außenbezug des Bildes zu seinem Hauptthema macht. Die dazu eingesetzte vieldeutige Gestik der Arme ist oben beschrieben worden, ebenso das Helldunkel und die Rolle des engelhaft-androgynen Lächelns. Dieses muss noch näher betrachtet werden, und zwar in Bezug auf die verschiedene Gestaltung der Augen. Das linke ist weit geöffnet, so dass das Weiß des Augapfels sichtbar ist. Es scheint den Betrachter anzuschauen, obwohl der Blick auch ein wenig nach oben geht, gleichsam der Bewegung des nach oben weisenden, hell beleuchteten Zeigefingers folgend. Das rechte hingegen ist fast ganz verschattet und dadurch weniger fokussiert. Es partizipiert also am Raumdunkel, während das andere mit der Lichtbahn des rechten Arms korrespondiert. In den verschiedenen Blickqualitäten inszeniert Leonardo also wiederum Gegenwart und Entrücktheit im Raum.

Genau diese beiden, im Helldunkel zusammentretenden Bewegungen ins Bild hinein und aus ihm heraus finden sich auch in Klees Bild. Die Augscheibe rechts wirkt freilich nicht sinnlich, da der Künstler ihren Konstruktcharakter ebenso wenig verbirgt wie ihre substanzielle Ähnlichkeit mit dem transzendenten Ziel, dem Gestirn. Leonardos Analogisierung des linken Auges von Johannes mit der dem Heilswerk Christi geltenden Zeigegeste scheint bei Klee also eine gleichsam buchstäbliche Entsprechung 
zu finden in der strukturellen Verwandtschaft von Gestirn- und Augscheibe. Die Arbitrarität der Diesseits-Jenseits-Konstellation wird offenkundig.

Das andere Auge des kristallinen Kopfgebildes nimmt durch sein Ausstrahlen wie das rechte Auge des Johannes auf das Innere des Bildes Bezug. Es stellt sich aber darüber hinaus als unmittelbarer Produktionsort des linearen Gerüsts dar, das einen quasi automatischen Gestaltwandel vollzieht, sich in viele einander überlagernde Rahmen auffächert, die eine unendliche Vervielfachung des Bildraums evozieren, um sich schließlich in eine Leiter zu verwandeln, die, wie beschrieben, als Richtungsweiser zur Erreichung des himmlischen Zielorts nicht funktioniert. Desavouiert wird bei Klee die Differenz zwischen dem Wesen und der Erscheinung, die Leonardo in der Figur des vom göttlichen Licht erfassten Johannes so eindrücklich präsentiert. Bei Klee ist alles letztlich aus einem Stoff, der Mensch und seine Bildproduktion, das Subjekt, sein Werkzeug und sein höheres Ideal. Wo Leonardo die Epiphanie des Heiligen durch eine malerische Evokation impulsiver Bewegung der betrachtenden Erfahrung zugänglich macht, parodiert Klee die Option auf wunderbare Grenzüberschreitung, indem er eine unendliche, scheinbar von mechanischer Absichtslosigkeit getriebene Verwandlungskraft der Linie und der Farbe inszeniert. Als Bedeutungsproduktion erschließt sich diese permanente Grenzüberschreitung nicht mehr durch den Rekurs auf außerkünstlerische Wahrheiten, sondern nur durch die Reflexion auf die Institution des Tafelbildes selbst. 